\title{
Energy Cost Optimization in a Water Supply System Case Study
}

\author{
Daniel F. Moreira ${ }^{1}$ and Helena M. Ramos ${ }^{1,2}$ \\ ${ }^{1}$ CEHIDRO, Instituto Superior Técnico, 1049-001 Lisbon, Portugal \\ ${ }^{2}$ Instituto Superior Técnico, 1049-001 Lisbon, Portugal \\ Correspondence should be addressed to Helena M. Ramos; hramos.ist@gmail.com
}

Received 21 December 2012; Revised 19 March 2013; Accepted 19 March 2013

Academic Editor: S. Venkata Mohan

Copyright (C) 2013 D. F. Moreira and H. M. Ramos. This is an open access article distributed under the Creative Commons Attribution License, which permits unrestricted use, distribution, and reproduction in any medium, provided the original work is properly cited.

\begin{abstract}
The majority of the life cycle costs (LCC) of a pump are related to the energy spent in pumping, with the rest being related to the purchase and maintenance of the equipment. Any optimizations in the energy efficiency of the pumps result in a considerable reduction of the total operational cost. The Fátima water supply system in Portugal was analyzed in order to minimize its operational energy costs. Different pump characteristic curves were analyzed and modeled in order to achieve the most efficient operation point. To determine the best daily pumping operational scheduling pattern, genetic algorithm (GA) optimization embedded in the modeling software was considered in contrast with a manual override (MO) approach. The main goal was to determine which pumps and what daily scheduling allowed the best economical solution. At the end of the analysis it was possible to reduce the original daily energy costs by $43.7 \%$. This was achieved by introducing more appropriate pumps and by intelligent programming of their operation. Given the heuristic nature of GAs, different approaches were employed and the most common errors were pinpointed, whereby this investigation can be used as a reference for similar future developments.
\end{abstract}

\section{Introduction}

Investigating efforts in new technological innovations are aimed to improving the energy efficiency of the several production sectors, which also applies to water supply companies [1, 2]. Energy consumption due to the pumping systems represents the biggest parcel of the energy expenses in the water sector-sometimes up to $90 \%$ [3]-and there are several practical solutions which can enable a reduction in these costs. Pump and motor upgrades to more efficient solutions, either being technologically more advanced or because they are more properly adjusted to the system, often allow significant energetic savings [4]. Also, changing the pumping operational procedures is very effective since it does not need any additional investment and because the economy with the reduction of the energy cost occurs immediately. The consumption of energy in most of the water systems all over the world could be reduced by at least $25 \%$ [5], only by improving the performance in terms of energy efficiency.

Operators of the water supply networks have a complex task in taking into account the distinct goals involved in this process. Determining operational rules to improve the quality of the service and that are also energetically economical, among an extensive set of possibilities, requires the utilization of models which take into consideration these components (FILHO, 2006).

Technological advances in the computational area enabled an increase in the quality of the scientific works related to model optimization, as well as reducing the energy cost of operation. Initially, investigations related to cost optimization of pumping expenses relied on operational research techniques as, for instance, linear programming [6,7], integral linear programming $[8]$, nonlinear programming $[9,10]$, and dynamic programming [11, 12]. Wood and Reddy (1994) [13] were the first to utilize genetic algorithms (GA) to reduce the energetic cost of pumping systems. These algorithms can be used as heuristic optimization models for achieving the best energy policy to be applied in a water supply system (WSS), enabling the determination of the optimal scheduling of control settings of pumps throughout each day.

The goal is to analyze a WSS, model it accordingly, and simulate several scheduling scenarios with optimized 
pumps in order to minimize the expenditure related to energy consumption, based on the demand patterns and associated energy tariffs.

\section{Background Review}

\subsection{Genetic Algorithms}

2.1.1. Nature and Applications. Genetic algorithms are stochastic methods of search that begin with a population of random chromosomes, which represent different solutions. The basic principles of the GA, widespread by Goldberg [14], are inspired in Darwin's evolutionary concept of survival of the fittest [15], evaluating each generation of individuals and allocating reproductive opportunities in such a way that those which represent a better solution to the target problem are given more chances to reproduce than those which are poorer solutions, numerically quantified as their fitness [16]. Convergence occurs as the chromosomes evolve to best fit the constrains of their environment.

These algorithms are commonly used to find optimal solutions in complex systems such as the scheduling of supply systems, where the amount of variables leads to vast possible solutions. There are a certain number of initial parameters that can be tuned, prior to the simulation, that affect the quality of the convergence.

2.1.2. Initial Parameters. Variations in the parameters that allow the GA to be tuned prior to the simulations influence the convergence process. In the current study, the main parameters considered were the population size (PS) of each generation, the elite population size (EPS) in each one of them, and the stopping criteria (SC) of the algorithm.

PS represents the number of individuals with different chromosomes that are created each generation. Smaller PS increases optimization speed but reduces reliability as there might not be enough genetic variety and only a less optimal part of the solution space is explored. On the other hand, too many chromosomes slow down the GA convergence [17].

EPS represents the amount of the fittest individuals from each generation that will be automatically chosen for the next one without being subject to crossover. This increases the performance of the GA, as it prevents the best found solutions to be lost if they were to be recombined. Nevertheless, increasing this value too much may lead to premature convergence to local optima.

SC is heuristic stopping criteria whose goal is ending the simulation after a limit number of generations without fitness improvement.

2.1.3. Best Practices. In pump scheduling it is possible to calculate the solution space $\left(S_{s}\right)$ given the number of possible decisions $\left(n_{d}\right)$ and the number of pump speed settings $\left(n_{s}\right)$, where the total solution space can be determined as being $S_{s}=n_{s} n_{d}$. To determine the solution space for two scenarios, one with 1 pump and the other with 2 pumps, with 2 possible drive speed settings each, in a 24-hour period with 1-hour discrete steps, the total would be $2^{1 \times 24}$ and $2^{2 \times 24}$ possible combinations, respectively.
It is not immediately obvious that the size of the solution space in optimization problems can quickly grow to overwhelming sizes. Adding a second pump in a scenario in which they can be turned on or off in a 24-hour period with 1-hour discrete steps increases the solution space almost 17 million times. It is therefore important to consider minimizing the number of pumps, the number of speed choices, and the duration and course of the simulation [18].

Any improvement that can be made towards reducing the duration of each individual simulation directly reduces the GA's overall run time. Consideration should be taken to keep the model size small and simple.

The nature of GAs implies that it has an inherent randomness associated with it. Therefore, two optimization runs that are otherwise identical except for one minor change (e.g., larger PS) will in all likelihood produce different optimized solutions. This is more likely to be the case the larger the solution space of the problem. It is a good practice to run multiple optimizations changing nothing other than one or more genetic algorithm parameters to ensure that the best optimized solution is really the best that can be achieved.

\subsection{Characteristic Curves. The pump characteristic curve} describes the relation between flow rate and total head for a specific pump (Figure 1). Other important information is also included, such as pump curves for different impeller diameters, net positive suction head curve (NPSH), and the efficiency and power curves [19].

In the case of the pump characteristic curves used, their designation determines its specific nominal diameter, in couple with nominal and actual impeller diameters (for the top curve in Figure 1). The pump's efficiency throughout its characteristic curve varies and should not drift too much from the best efficiency point (BEP). The motors rotating the shaft that moves the impeller, whose pole number is referenced in the pump designation, also have their own efficiencies that must be considered.

The system characteristic curve describes graphically the variation of head $(H)$ given different flows $(Q)$, according to an equation which depends on the pipe diameter $(d)$ and its specific roughness coefficient $(K)$. In this case, the HazenWilliams empirical formula was used (1):

$$
H=\frac{10.67 Q^{1.65}}{K^{1.85} d^{4.87}} .
$$

The operation point in the pump curve is dependent upon the characteristics of the system in which it is operating. The system head curve is the graphic representation of the energy equation, or the relationship between flow and hydraulic losses in a system. Figure 2 shows that, by plotting both the system head curve and pump curve together, the pump's operating point $\left(Q_{1}, H_{1}\right)$ can be determined.

When two or more pumps are arranged in parallel, their resulting performance curve is obtained by adding their flow rates at the same head as indicated in Figure 2. The operating point at the intersection of the resulting curve $\left(Q_{2}, H_{2}\right)$ represents a higher volumetric flow rate than for a single pump and a greater system head loss. In the case of 

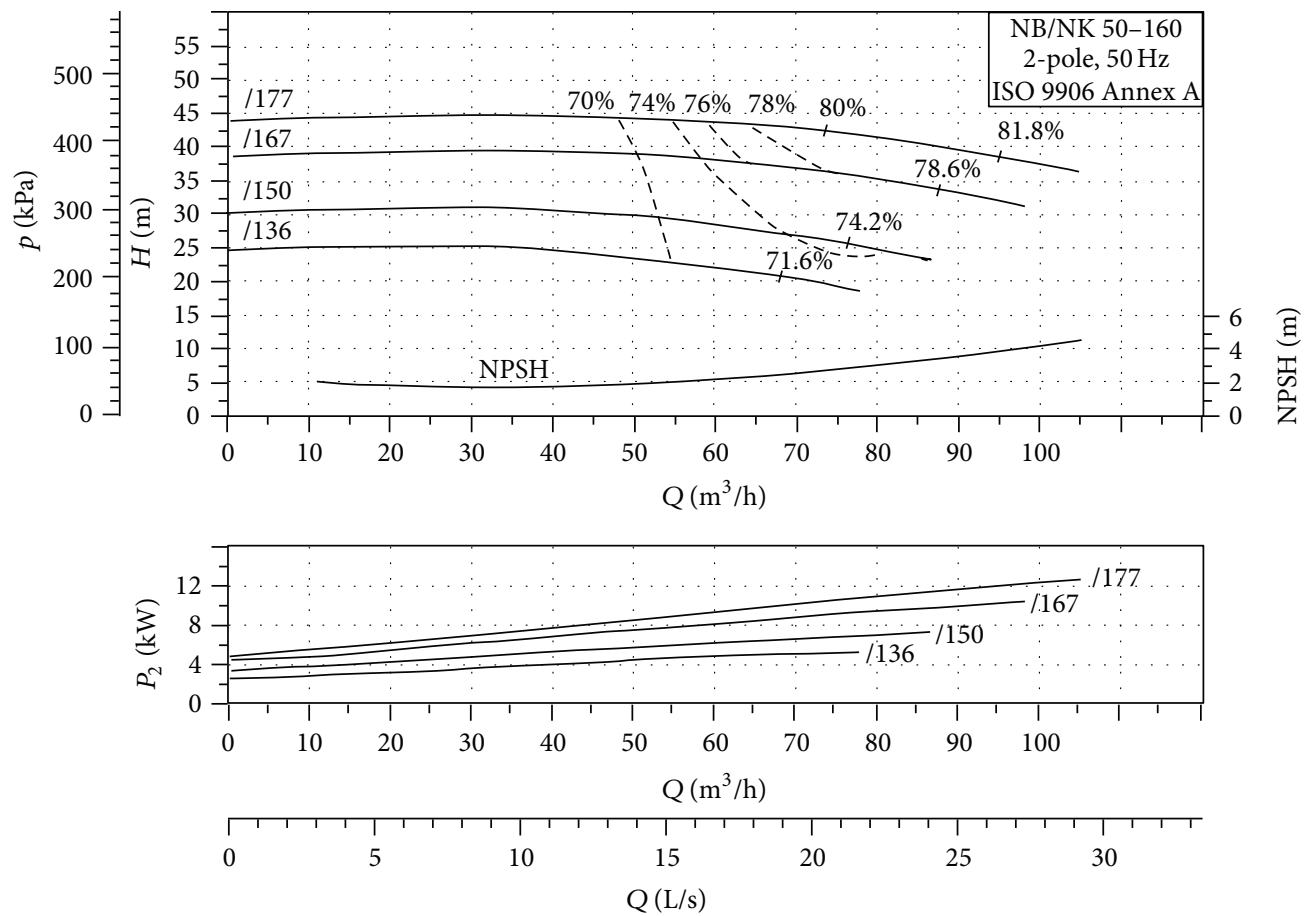

FIgURE 1: Example of a pump curve.

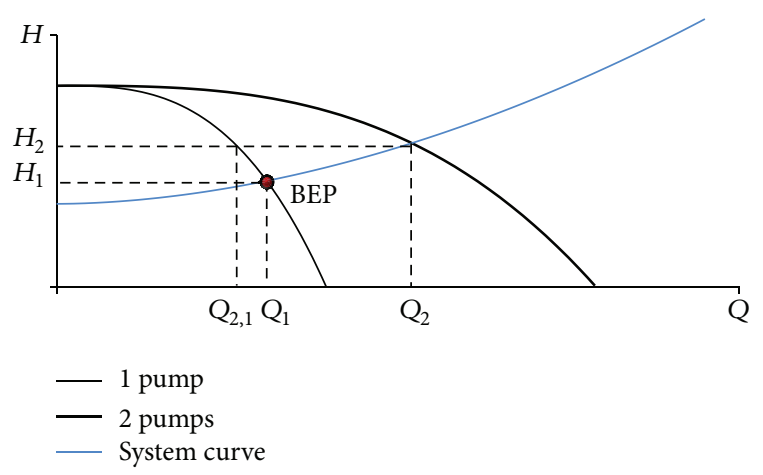

FIGURE 2: Graphic representation of one system curve intersecting two pump curves.

two similar pumps, because of the greater system head, the volumetric flow rate is actually less than twice the flow rate achieved by using single pump [19].

When using pumps with operation points next to their $\operatorname{BEP}\left(Q_{1}, H_{1}\right)$, it is not recommended to run them in parallel, since they will be operating at less efficient flows $\left(Q_{2,1}, H_{2}\right)$.

The affinity laws expressed in (2) represent the mathematical relationship between the speed $(n)$, discharge $(Q)$, head $(H)$, and water power $(P)$ of a pump.

$$
\frac{n_{1}}{n_{2}}=\frac{Q_{1}}{Q_{2}}=\sqrt[2]{\frac{H_{1}}{H_{2}}}=\sqrt[3]{\frac{P_{1}}{P_{2}}} .
$$

There are different ratios between the pump's speed and the other variables. A reduction of $10 \%$ in pump speed translates into a $27 \%$ reduction in power consumption. It must be noted that this also reduces the pump head in $19 \%$.
For variable-speed-driven (VSD) pumps, small speed variations of the shaft-directly proportional to the flowtranslate into significant pump power variations, which can increase the efficiency of the pumping operation when compared to pumps equipped with fixed-speed drives (FSD). Nevertheless, this also affects the pump head, rendering it inoperable below the point where it will not cross the system curve.

According to [19], as these points come closer to each other and the system curve becomes tangent to the pump curve, the operation of the pump becomes extremely unstable if transient regimes occur. Besides, the pump curve can have a shut-off head inferior to the system curve, meaning that the pump is not able to start at that particular speed without a bypass.

\section{Case Study}

3.1. Water Supply System Selection. The supply system for this case study was chosen following the investigation of Costa and Ramos (2010) serving the demands of the Fátima region, in Portugal. In reality, the pumping station is comprised of two NK 65-250 type pumps with an average pumped flow of $42 \mathrm{l} / \mathrm{s}$, with an overall efficiency of $60 \%$. Since the goal was to test a better type of GA, the pump curve utilized had a constant discharge for all heads and the efficiency was invariable. Thus, these simplifications imply that the data obtained in terms of energy cost should be considered less than accurate, but relevant, proving that GA scheduling optimization can improve considerably the efficiency of a pumping operation.

Figure 3 represents the WSS modeling. The water is pumped through a $250 \mathrm{~mm}$ diameter pipe with a HazenWilliams roughness coefficient of 145 , spanning for $1,607.8 \mathrm{~m}$ 

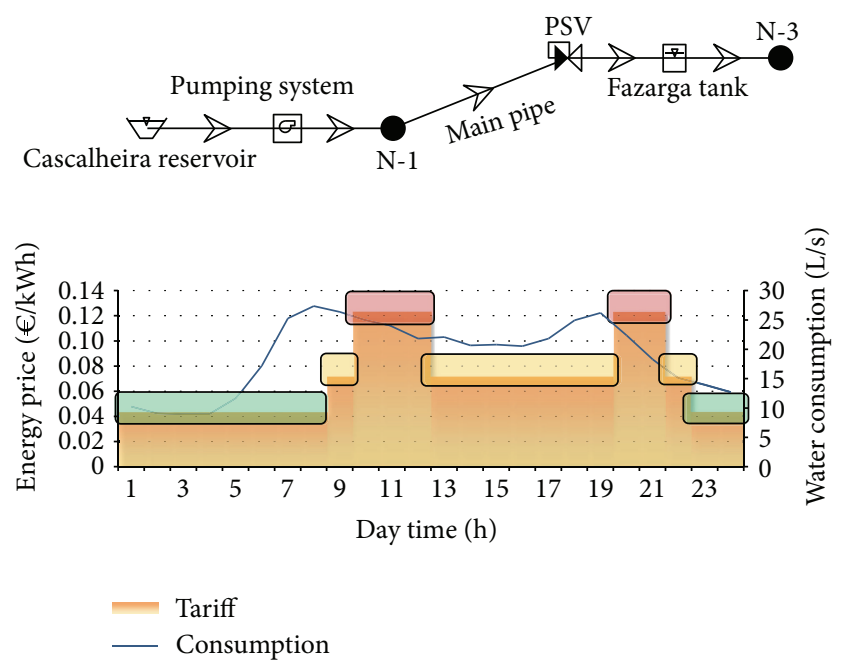

Figure 3: Computational model of the pump system (top), daily energy tariff and water consumption in node N-3 (bottom).

and connecting the Cascalheira reservoir (elevation: $375.3 \mathrm{~m}$ ) to the Fazarga tank ( $405.0 \mathrm{~m}$ ).

The tank has a volume of $347.0 \mathrm{~m}^{3}$ when full, but it operates only beyond a $45.3 \mathrm{~m}^{3}$ minimum reserved for emergencies, and therefore the effective total is of $301.7 \mathrm{~m}^{3}$. For this study the average daily consumption is of $191 / \mathrm{s}$, which represents an average of 4 hours and 24 minutes of available water with a full tank.

Node N-3 was considered the consumption node, simulating the daily water demand variation, based on information from sensors placed downstream the Fazarga tank. There must be also an energy tariff associated with the model, so the simulation can calculate the energy consumption.

According to lanscy and awumah (1994), increasing the number of actions per operational cycle proportionally increases the wear of the pumps. Therefore, this value was limited to a recommended daily maximum of three cycles per pump.

3.2. Simulation Scenarios. Two distinct models were considered to simulate the studied system. These have different model complexities and solution spaces, as well as particular operational modes.

3.2.1. Two Pumps with Three Starts (2 Pump/3). This scenario comprises two pumps, operating independently of each other with a maximum of three start/stop cycles per pump per day. It allows more versatile solutions as the pumps can operate in parallel with independent speeds at the same time, but it is also the option with the biggest solution space and system complexity of all. In addition, when two pumps operate in parallel, the overall operation point changes a potential less efficient one if the pumps are already correctly dimensioned to operate near their BEP.

3.2.2. One Pump with 6 Starts (1 Pump/6). This scenario comprises one pump which can start up to six times per day,

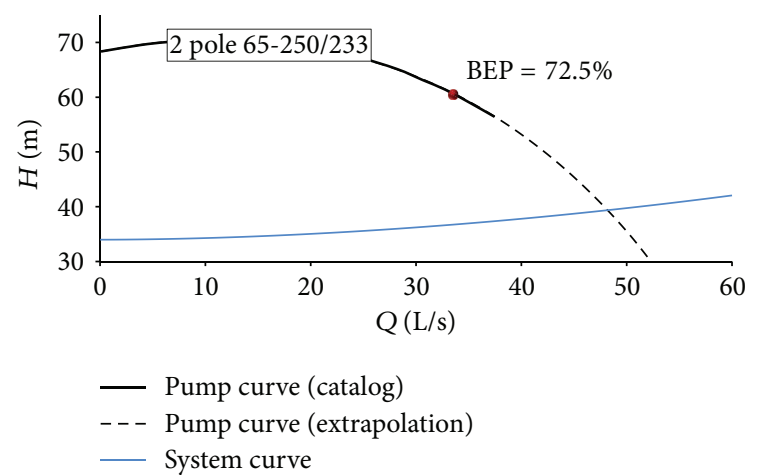

FIGURE 4: Original Veolia pump curve compared to the system curve.

TABLE 1: Solution spaces for each simulation approach for $1 \mathrm{~h}$ time steps in a $24 \mathrm{~h}$ period.

\begin{tabular}{lcc}
\hline Scenario & Off/On & $S_{s}$ \\
& $1.68 E+07$ & $\mathrm{Off} / I_{1} / I_{2} / I_{3} / I_{4} / \mathrm{On}$ \\
\hline 1 pump/6 & $2.81 E+14$ & $4.74 E+18$ \\
2 pump/3 & $2.25 E+37$ \\
\hline
\end{tabular}

emulating two pumps with three starts each but which cannot operate simultaneously. When the pumps are prevented to operate in parallel, it guarantees that the pumping occurs always at the same operating point. Therefore, the computational model has to balance the equations for only one pump, which reduces the simulation time. Furthermore, the solution space is also considerably reduced, along with versatility loss in the potential operational strategies.

Table 1 shows a comparison between solution spaces of these scenarios when combined with both FSD and VSD scenarios. These actions vary between a simple on/off operation to the possibility of intermediate speeds in a pump equipped with a VSD motor. It must be also noted that, in simulations with four intermediate speeds, the 1 pump/ 6 approach has almost five quintillion times less possible solutions than its 2 pumps/3 counterpart.

3.3. Selection of the Pump and Motor. The total supply needs of the population must be met by the operation of only one pump, whereby the discharge flow must be superior to the average daily demand $(20 \mathrm{l} / \mathrm{s}<Q<40 \mathrm{l} / \mathrm{s})$, having also considered pumps with a flowup to double that value. In relation to the total head, the pumps should comprise a range which take into account the increase in roughness of the pipes over time $(32 \mathrm{~m}<H<38 \mathrm{~m})$.

Based on the pump curve, Figure 4 highlights the fact that the pumps used by Veolia do not seem appropriate for this WSS and are probably operating with reduced efficiency. With pump efficiency at BEP of $72.5 \%$ and considering a motor with $92 \%$ efficiency, the total efficiency at that point is of $66.7 \%$. Since the operating point is far from the BEP, a total efficiency of $60 \%$ was determined as reasonable. The operational cost resulting from energy consumption was of $22.2 € /$ day $(12 / 07 / 2007)$. All subsequent simulations were 


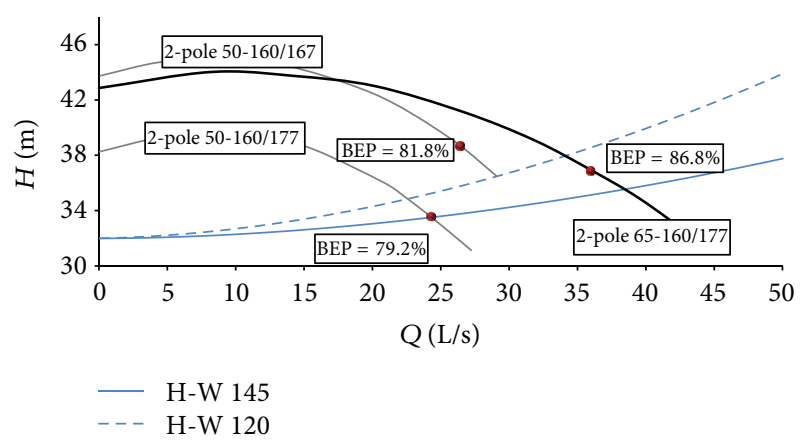

FIgURE 5: Pump curves of the considered pumps compared to system curves with two different roughness (Hazen-Williams coefficients of 145 and 120).

performed using the energy tariffs and consumption curves practiced at that time for coherence in comparison.

Using the Grundfos pump catalogue, three 2-pole motor pumps which fitted the considered flow and head ranges were selected for testing. Their characteristic curves were extracted from their specification manuals and input in the modeling software. Since pipe roughness can increase over time, these curves were compared against system curves which represent both present and future scenarios (Figure 5).

(i) Pump 50-160/177 does not seem appropriate, since the pump curve extracted from the catalogue does not intersect the system curve, meaning that it would operate with flows which are not recommended by the manufacturer;

(ii) Pump 50-160/167 has a discharge flow near to the average daily demand, increasing its probability of becoming obsolete if the demand is intensified or if the flow is reduced due to a pipe roughness increase over time. The maximum efficiency is also inferior to the $65-160 / 177$ and, if equipped with a VSD, the possible speed range is minor given its inferior total heads.

The selected pump for comparison with the current one was, therefore, the 65-160/177 equipped with a 2-pole motor $\left(X_{1}\right)$.

By comparison to the system curve, it is relevant to determine the speed range in which this pump can operate so the solution space does not include unnecessarily unfeasible solutions. The affinity laws allow the determination of new curves based on the original one for different drive speeds. Figure 6 shows that in order to avoid system instability, the minimum motor speed should be of $87 \%$.

\section{Results}

4.1. General Considerations. It is always preferable to operate the pumps at off-peak hours $\left(T_{1}\right)$, as the pumping costs due to electricity consumption for the same volume are inferior. A sufficiently large tank would have enough storage capacity to be filled during those periods, avoiding pumping during peak hours. Two different approaches were studied in order

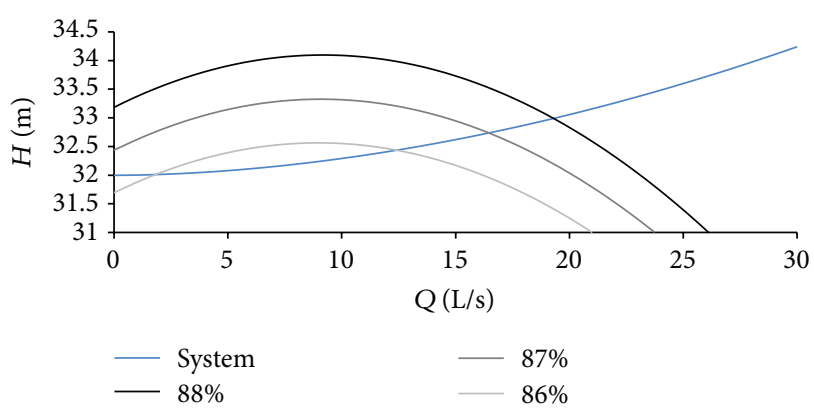

FIGURE 6: 65-160/177 pump curve operating at three different speeds when compared to the system curve.

to cope with the fact that the volume of the tank is limited. The demand curve and energy tariff have a repetitive $24 \mathrm{~h}$ pattern; thus a daily cycle was considered in the simulations. Thus, the tank must finish the cycle with the same water level as it began, in order to prevent volume variations throughout the days.

The commercial software used for these simulations was Bentley's WaterGEMS, which has embedded in it a genetic algorithm simulation module (Darwin Scheduler).

4.2. Manual Management. In order to be properly compared with the existing scenario, the model was tested with a simulation using the original operational scheduling using the original pump $\left(X_{0}\right)$ and the 65-160/177 pump $\left(X_{1}\right)$. Subsequently, a manual optimization approach was carried out with the goal of determining an operational strategy which sought to restrict operations during semipeak $\left(T_{2}\right)$ and peak $\left(T_{3}\right)$ hours, while guaranteeing a stable supply. The next step was to broaden those intervals during which the pumps were not operating.

The energy cost of operation obtained from the calibration $(22.1 € /$ day) was similar to the real data provided by Veolia $(22.2 € /$ day), corroborating the reliability of the hydraulic simulation model. This operational regime imposes five pump starts, which probably means that the two pumps took turns so that the daily three starts limit is not exceeded.

In Figure 7, the utilization of pumps during peak hours (12:00-13:00 and 21:00-22:00) was verified. Pump $X_{1}$ operated with a total efficiency of $78.9 \%$, a $13.9 \%$ difference comparing to pump $X_{0}$. Pumps $X_{0}$ and $X_{1}$ operated with discharge flows of $41.8 \mathrm{l} / \mathrm{s}$ and $38.7 \mathrm{l} / \mathrm{s}$, respectively.

Pump $X_{1}$ managed to complete the daily cycle within the maximum and minimum limits of the tank, operating with a discharge flow similar to the $X_{0}$ and finishing without tank volume variation (Figure 8 ). The operational cost of the pump ( $15.1 € /$ day) was $32.0 \%$ less than the one practiced by Veolia even without an optimized scheduling pattern, which is directly related to the increase in pump efficiency.

After the verification of these results, the heuristic manual optimization was performed operating only one pump at each time and with FSD motors. This strategy can be inferred from Figure 9. Both pumps operated within the tank limits, completing the daily cycle without volume variation (Figure 10). 


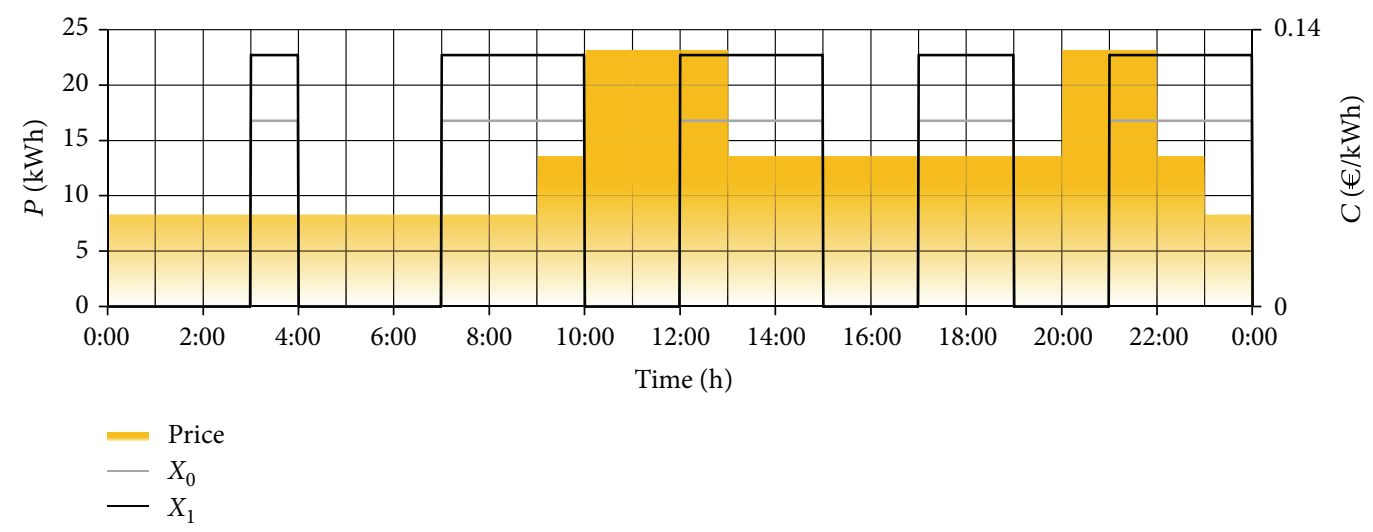

FIGURE 7: Pump power consumption for the original strategy and energy tariff.

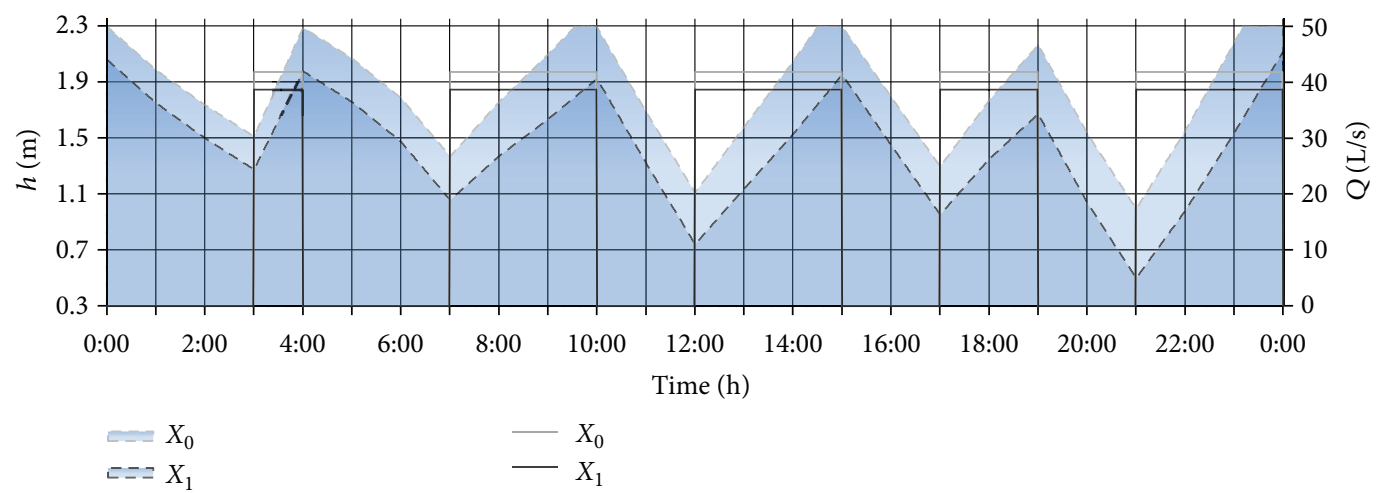

FIgURE 8: Flow and tank water level for the original strategy.

The operational costs of optimized pumps $X_{0}$ and $X_{1}$ are of $17.5 € /$ day and $13.1 € /$ day, less $21.1 \%$ and $41.0 \%$ than the initial scheduling strategy, respectively.

4.3. Genetic Algorithm Approach. This approach tests thousands of simulations in order to select the fittest of all given the system in which they are. Harnessing the applicability of these algorithms in complex scenarios, in these simulations two parallel pumps were allowed to operate, which represents an increase in versatility when compared to the manual override approach. Since the software could not simulate the original pump curve due to its maladjustment to the system at issue, no GA simulations were performed for this pump.

With VSD pumps it was allowed a total of six possible actions: pump turned off, minimum speed, three intermediate speeds, and maximum speed. The tradeoff was to allow some continuity in the speed steps while minimizing the solution space. The model was restricted by the number of pump starts and the tank minimum and maximum water levels, and the heuristic stopping criterion was a maximum of 200 generations without solution fitness improvement.

In the original Costa et al. investigation, all the daily cycles started at 0:00 h for an initial tank water level of $2.00 \mathrm{~m}$. This fact implied that the algorithm should guarantee that level at that specific hour, even if it would mean to pump at least advantageous periods. Thus, four different initial water levels $\left(h_{\text {initial }}\right)$ were tested for each pump and motor-0\%, 25\%, $50 \%$, and $75 \%$ of the effective volume, that is, $0.30 \mathrm{~m}, 0.80 \mathrm{~m}$, $1.30 \mathrm{~m}$, and $1.80 \mathrm{~m}$, respectively.

In order to overcome the inherent randomness of the convergence of the GA, four different simulations were performed for each water level and pump/motor type, varying the initial GA parameters with a PS of 100 and 200 individuals and EPS of 10 and 20 individuals. The total number of performed GA simulations resulting from these combinations was of 96.

Figures 11 and 12 show the daily cost results for each scenario and water level considered. It is immediately visible the influence of both initial tank water level and initial GA parameters from the scattered results. This is more pronounced in the FSD results, where the minimum result achieved was of $13.3 €$ /day by comparison to a maximum of $16.5 € /$ day.

Figures 13 and 14 present the results for the best solutions achieved. The daily operational cost was of $13.1 € /$ day and $12.5 € /$ day for the $X_{1}$ pump with both FSD and VSD motors, respectively. When analyzing the VSD motor results, it can be concluded that the increase in versatility of solutions allowed by this motor compensates its inferior efficiencies. The fact that the pump operates at lower speeds-it never reaches maximum speed-and only has need for 3 daily starts becomes an advantage in terms of pump life expectancy and 


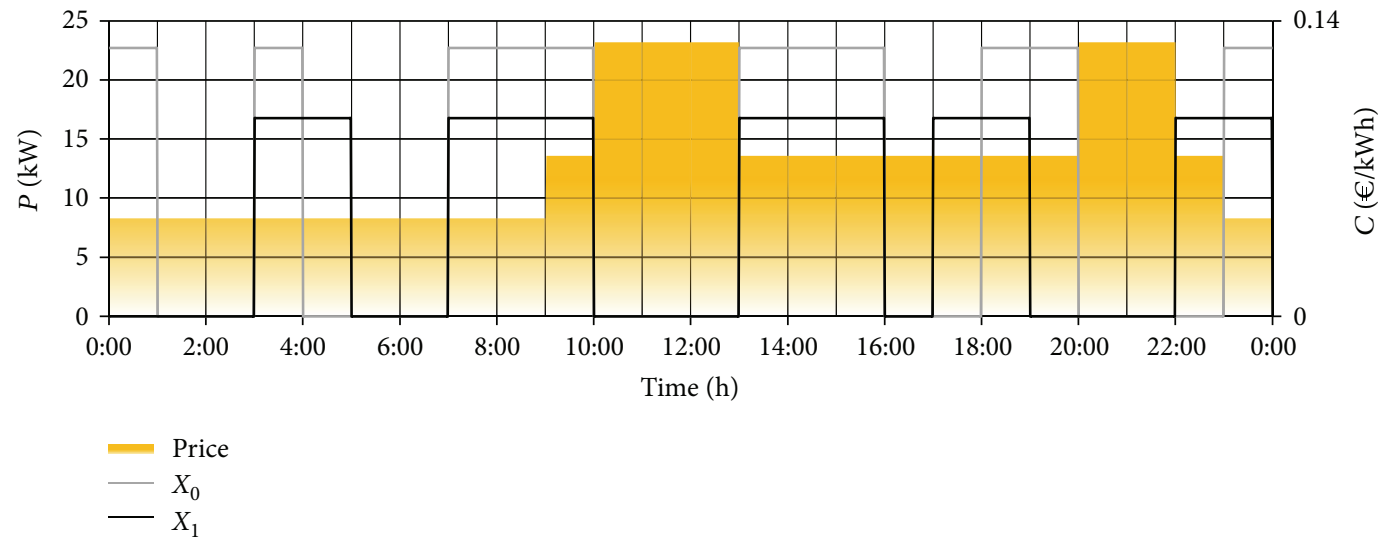

FIGURE 9: Pump power consumption for the manually optimized strategy and energy tariff.

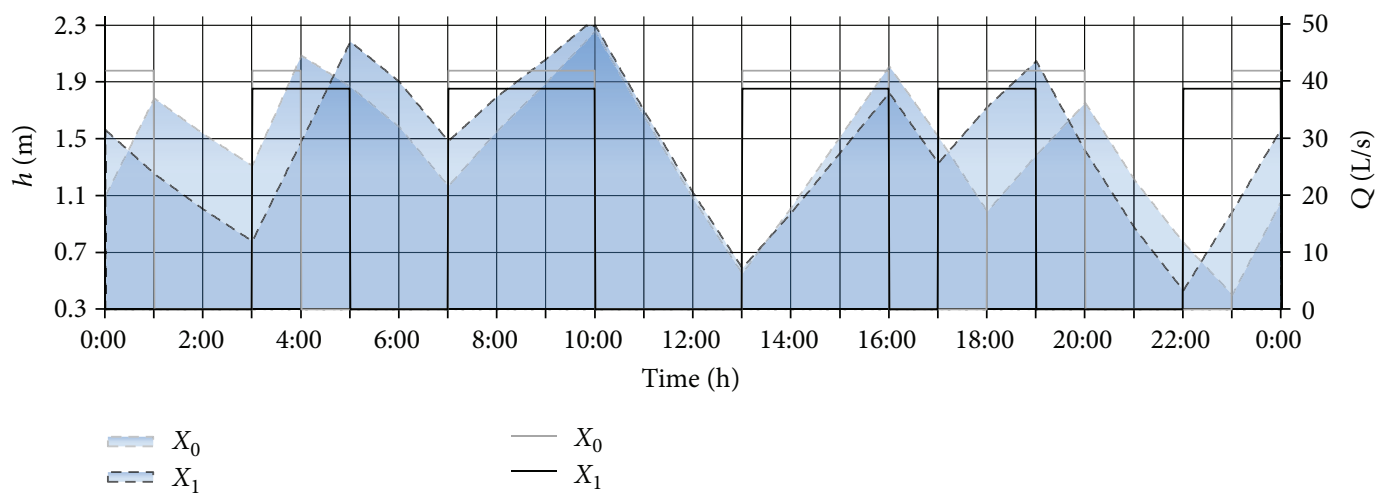

Figure 10: Flow and tank water level for the manually optimized strategy.

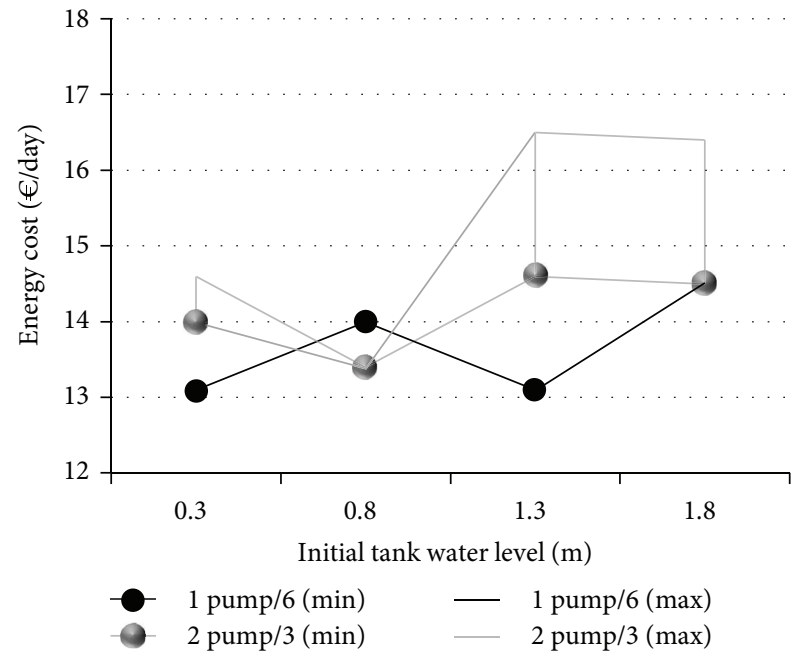

Figure 11: $\mathrm{B}_{1}$ FSD.

maintenance when compared to the FSD, which operates at maximum speed and has 4 daily starts.

It is possible that the worst results obtained for the FSD are justified by the difficulty in matching a daily cycle without volume variation for $1 \mathrm{~h}$ control intervals. Also, the VSD can better adapt the supply to the demand by varying flow, reducing power as necessary.

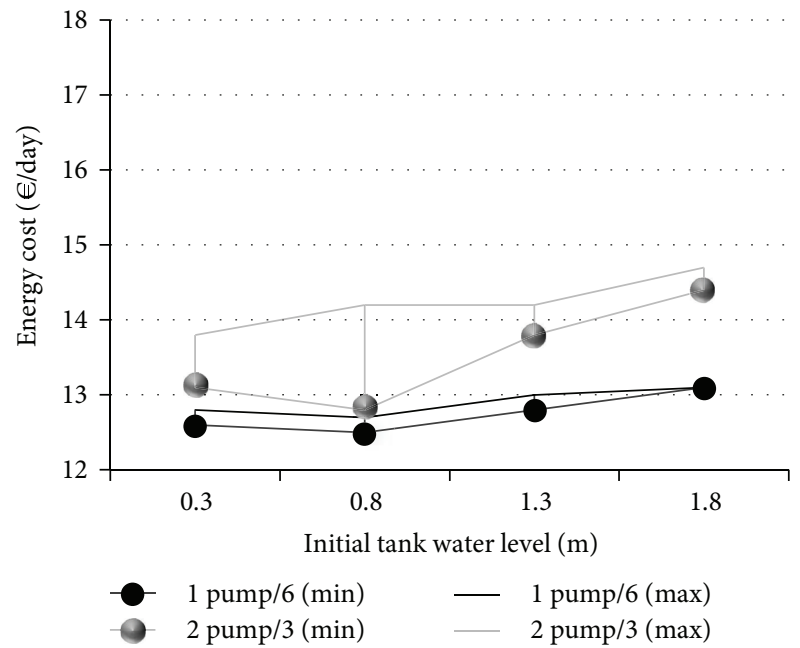

Figure 12: $\mathrm{B}_{1}$ VSD.

Table 2 compiles data from the simulation runs considering different initial tank and water levels. It should be noted that different GA parameters produced different results.

Systematized in Table 3 is the power consumption of each pump/motor system, as well as its operating hours at different energy tariffs, the tank water level, overall pump efficiencies, and energy cost. 


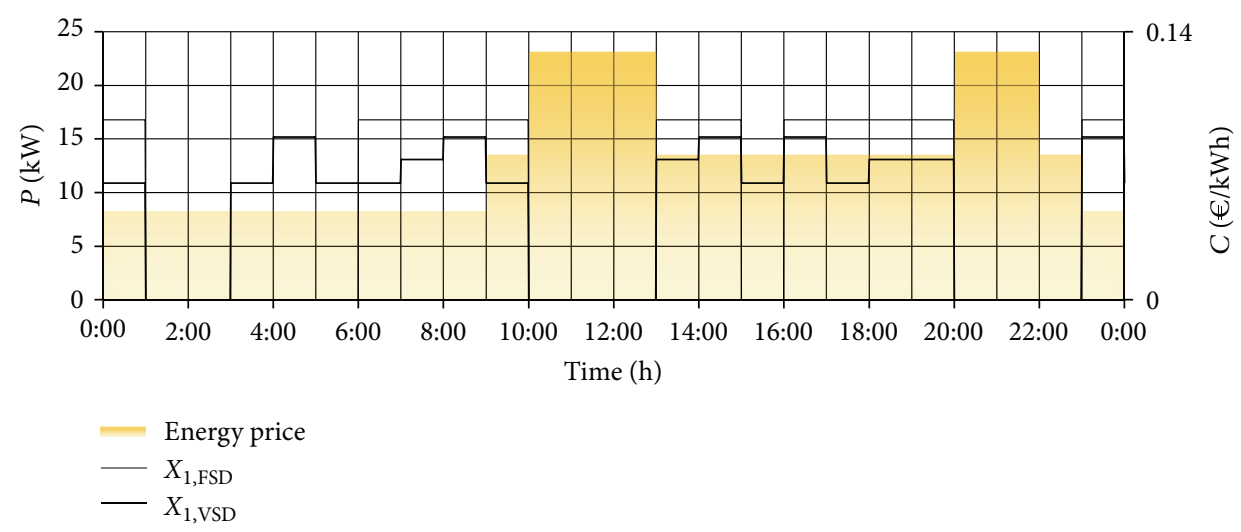

(a)
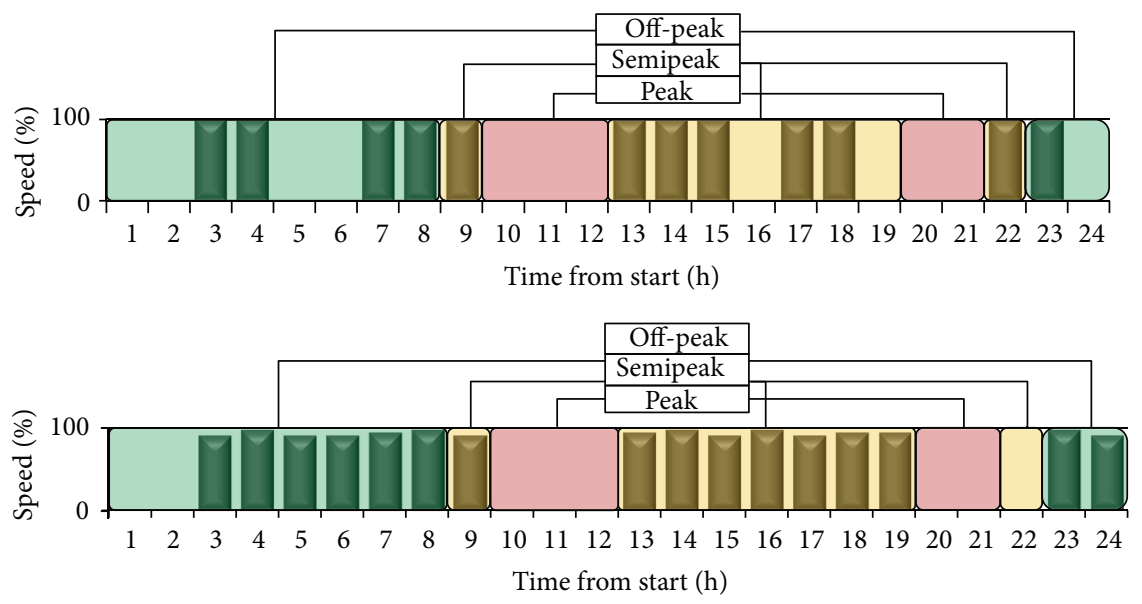

(b)

FIGURE 13: Pump power consumption for the best AG solution and energy tariff (top) and scheduling operations pattern for the $X_{1}$, FSD and the $X_{1}$, VSD pumps, with the genetic algorithm optimization.

TABle 2: Minimum operational costs achieved for the different simulation scenarios and respective standard deviation between simulation runs with different initial parameters.

\begin{tabular}{cccccccccc}
\hline \multicolumn{2}{c}{$h_{\text {initial }}(\mathrm{m})$} & \multicolumn{2}{c}{0.30} & \multicolumn{2}{c}{0.80} & \multicolumn{2}{c}{1.30} & \multicolumn{2}{c}{1.80} \\
\multicolumn{2}{c}{$C(€ /$ day $)$} & Min & $\sigma$ & Min & $\sigma$ & Min & $\sigma$ & Min & $\sigma$ \\
\hline \multirow{2}{*}{ GA X $_{1, \text { FDS }} 1$ pump/6 } & 13.1 & 0.0 & 14.0 & 0.0 & 13.1 & 0.0 & 14.5 & 0.0 \\
& 2 pump/3 & 14.0 & 0.3 & 13.4 & 0.0 & 14.6 & 1.0 & 14.5 & 0.8 \\
\hline \multirow{2}{*}{ GA X X $_{1, \text { VDS }} 1$ pump/6 } & 12.6 & 0.1 & $\mathbf{1 2 . 5}$ & 0.1 & 12.8 & 0.1 & 13.1 & 0.0 \\
& 2 pump/3 & 13.1 & 0.3 & 12.8 & 0.6 & 13.8 & 0.2 & 14.4 & 0.1 \\
\hline
\end{tabular}

\section{Conclusions}

The solutions obtained from optimization processes produced considerable superior results when compared to the original strategy, with the best solution allowing a $43.7 \%$ savings. It is advisable to develop a cash flow analysis to the option of installing new pumps, as well as to introduce integrated dynamic monitoring systems which would allow a real-time optimization of the scheduling of the pumps, both in new projects and in existing WSS.

It is possible to conclude that these algorithms are susceptible to the initial parameters input in the beginning of the simulation and to the size of the solution space. Consequently, it is essential to perform several simulations in order to overcome this disadvantage, as well as considerations in minimizing the model complexity. A careful and critical analysis of the solutions obtained is also indispensable to achieve the most efficient strategies.

Satisfactory results were obtained with a manual override optimization process, when compared to the GA, given the fact that the criteria were primarily to avoid consumption in peak hours and to prevent volume variation in the tank. By contrast, the GA runs many simulations and it is essential to optimize more complex scenarios, such as those with interaction between pumps. Furthermore, it was demonstrated that given the stochastic nature of this algorithm, its usage requires careful considerations of all the variables involved in order to achieve the best possible results. Hence, it is vital to carefully consider good practices in GA optimization. The results obtained by the 1 pump/ 6 scenario are not only the best but also more consistent than the ones obtained from the 2 pump/3. This points to a systematic convergence towards an optimal solution and demonstrates the importance of model complexity and solution space in obtaining the best results. 
TABLE 3: Relevant data from each scenario.

\begin{tabular}{lcccccccccc}
\hline & $P(\mathrm{~kW})$ & $T_{1}(\mathrm{~h})$ & $T_{2}(\mathrm{~h})$ & $T_{3}(\mathrm{~h})$ & $\mathrm{Q}(\mathrm{l} / \mathrm{s})$ & $h_{\min }(\mathrm{m})$ & $h_{\max }(\mathrm{m})$ & $\eta(\%)$ & $C(€ /$ day $)$ & $\Delta(\%)$ \\
\hline$X_{0}$ & 24.6 & 4 & 6 & 2 & 41.8 & 0.99 & 2.30 & 60.0 & 22.1 & 0.5 \\
$X_{1, \text { FSD }}$ & 16.8 & 4 & 6 & 2 & 38.7 & 0.50 & 2.12 & 78.9 & 15.1 & 32.0 \\
MO $X_{0}$ & 24.6 & 5 & 6 & 0 & 41.8 & 0.40 & 2.26 & 78.9 & 17.5 & 21.2 \\
MO $X_{1, \text { FSD }}$ & 16.8 & 5 & 7 & 0 & 38.7 & 0.43 & 2.30 & 78.9 & 13.1 & 41.0 \\
GA $X_{1, \text { FDS }}$ & 16.8 & 5 & 7 & 0 & 38.7 & 0.38 & 2.13 & 78.9 & 13.1 & 41.0 \\
GA $X_{1, \text { VDS }}$ & $12.8^{*}$ & 8 & 8 & 0 & $28.9^{*}$ & 0.32 & 2.28 & $74.7^{*}$ & $\mathbf{1 2 . 5}$ & 43.7 \\
\hline
\end{tabular}

${ }^{*}$ Given the different possible drive speeds, this is an average value.

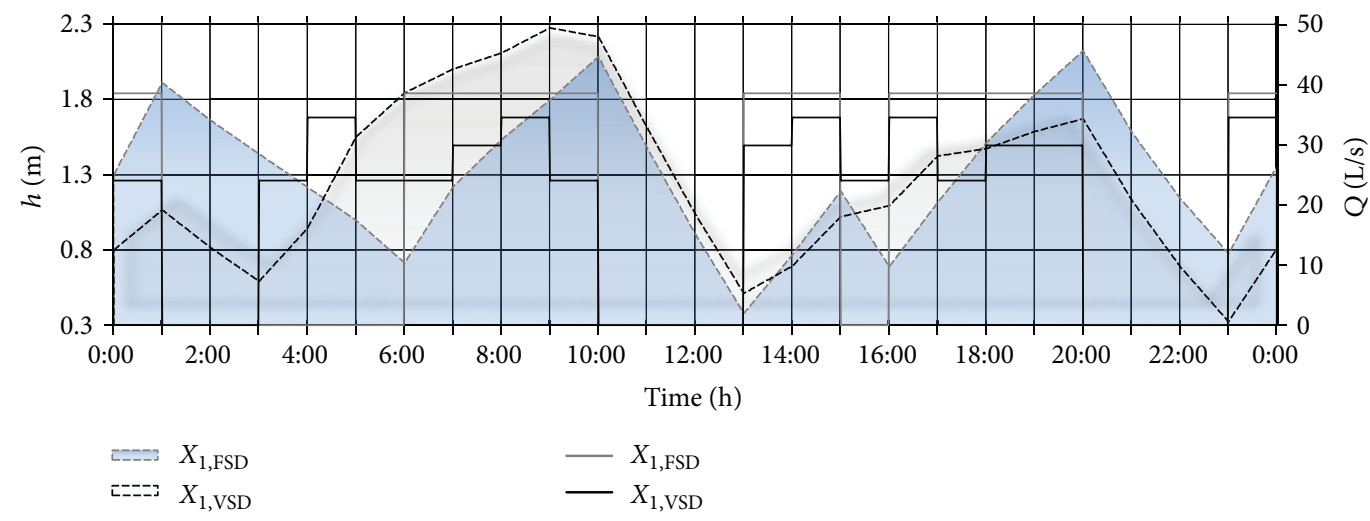

FIGURE 14: Flow and tank water level for the best AG solution.

\section{References}

[1] M. A. Braghiroli, M. B. dos Santos, and D. B. Filho, Estação Elevatória de Água de Santana: Um Caso de Sucesso Na Redução de Perdas E Consumo de Energia No Setor de Saneamento, Cleaner Production Initiatives and Challenges for a Sustainable World, 2011.

[2] L. H. M. Costa, H. M. Ramos, and M. A. H. Castro, "Hybrid genetic algorithm in the optimization of energy costs in water supply networks," Engenharia Sanitaria E Ambiental, vol. 15, no. 2, 2010.

[3] Grundfos, Pump Handbook, Management A/S Grundfos, 2004.

[4] M. Tsutiya, Redução do Custo de Energia Elétrica em Sistemas de Abastecimento de Água, ABES, 2001.

[5] M. Tsutiya, Abastecimento De Água, Departamento de Engenharia Hidráulica e Sanitária da USP, São Paulo, Brazil, 2nd edition, 2004.

[6] P. W. Jowitt and G. Germanopoulos, "Optimal pump scheduling in water-supply networks," Journal of Water Resources Planning and Management, vol. 110, no. 1, pp. 17-35, 1992.

[7] D. Burnell, J. Race, and P. Evans, "An overview of the trunk scheduling system for the London Ring Main," Water Science and Technology, vol. 28, no. 11-12, pp. 99-109, 1993.

[8] K. W. Little and B. J. McCrodden, "Minimization of raw water pumping costs using MILP," Journal of Water Resources Planning and Management, vol. 115, no. 4, pp. 511-522, 1989.

[9] D. V. Chase and L. E. Ormsbee, "Computer-generated pumping schedules for satisfying operational objectives," Journal of the American Water Works Association, vol. 85, no. 7, pp. 54-61, 1993.

[10] G. Yu, R. S. Powell, and M. J. H. Sterling, "Optimized pump scheduling in water distribution systems," Journal of Optimization Theory and Applications, vol. 83, no. 3, pp. 463-488, 1994.
[11] M. J. H. Sterling and B. Coulbeck, "A dynamic programming solution to the optimization of pumping costs, in Hybrid genetic algorithm in the optimization of energy costs in water supply networks," ICE Proceedings, vol. 59, no. 2, pp. 813-818, 1975.

[12] K. E. Lansey and K. Awumah, "Optimal pump operations considering pump switches," Journal of Water Resources Planning and Management, vol. 120, no. 1, pp. 17-35, 1994.

[13] D. J. Wood and L. S. Reddy, "Control de bombas de velocidad variable y modelos en tiempo real para minimizar fugas y costes energéticos," in Mejora del Rendimiento y de la Fiabilidad en Sistemas de Distribución de Agua, pp. 173-207, Universidad Politécnica de Valencia, Universitat Jaume I de Castellón, Valência, Spain, 1994.

[14] D. E. Goldberg, Genetic Algorithm is Search Optimization and Machine Learning, Addison-Wesley Longman Publishing, Boston, Mass, USA, 1989.

[15] C. Darwin, On the Origin of Species, Wordsworth Limit, 1998.

[16] D. Whitley, "A genetic algorithm tutorial," Statistics and Computing, vol. 4, no. 2, pp. 65-85, 1994.

[17] J. Koljonen and J. T. Alander, Effects of Population Size and Relative Elitism on Optimization Speed and Reliability of Genetic Algorithms, Department of Electrical Engineering and Automation, University of Vaasa, Vaasa, Finland, 2006.

[18] Bentley Systems, WaterGEMS V8i User's Guide, Bentley, 2009.

[19] A. Quintela, Hidráulica, Fundação Calouste Gulbenkian, Lisboa, Portugal, 2002. 


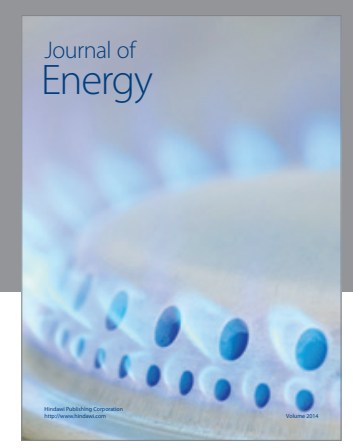

Journal of

Industrial Engineering
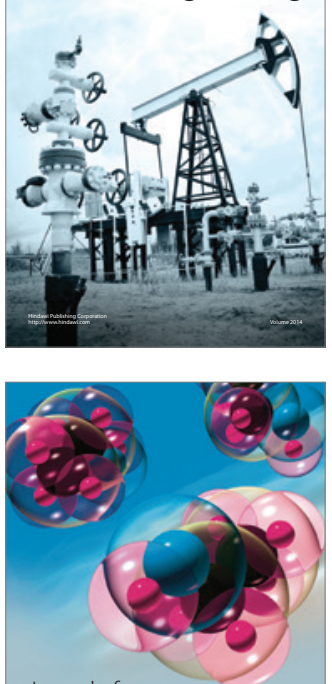

Fuels
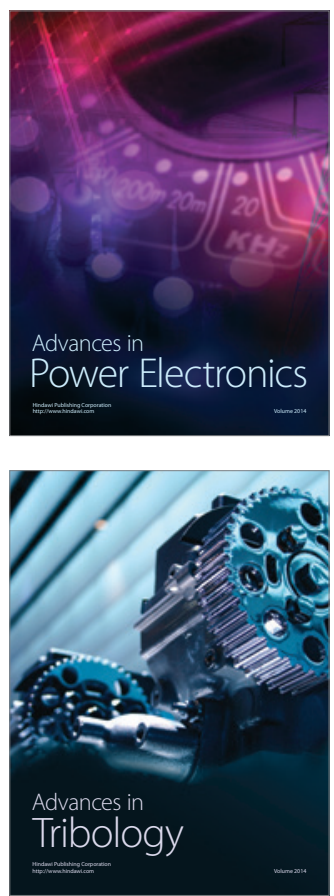

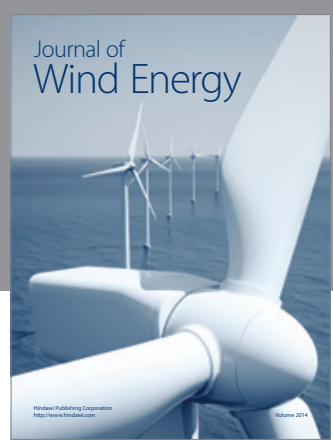

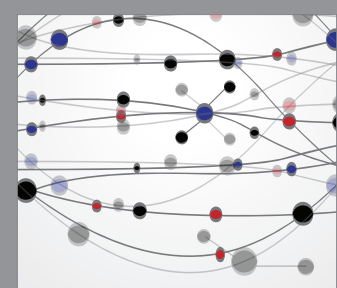

The Scientific World Journal

Submit your manuscripts at http://www.hindawi.com

Journal of

Structures
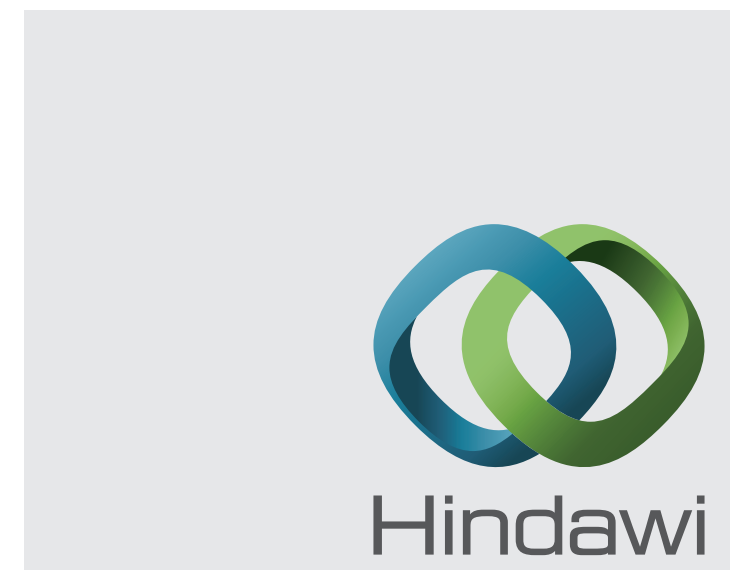

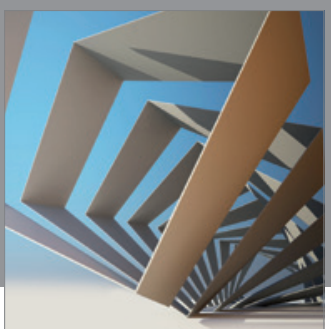

Rotating

Machinery
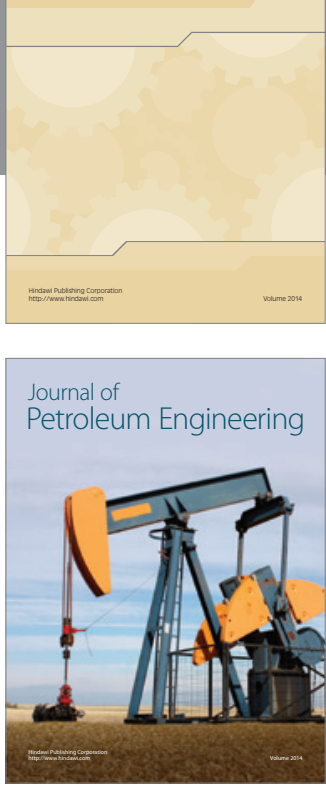

Journal of

Solar Energy
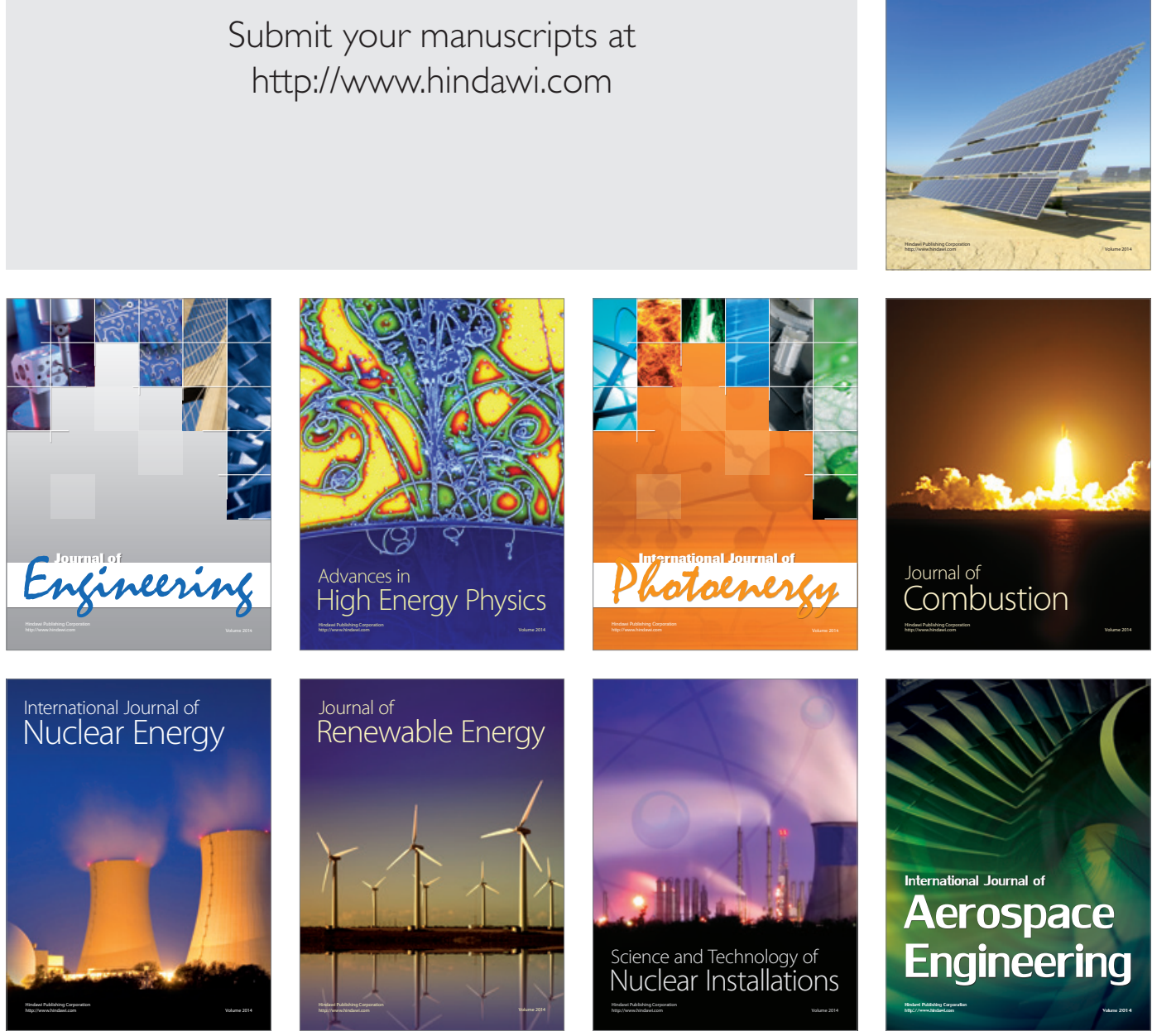